\title{
DHEA and frontal fibrosing alopecia: molecular and physiopathological mechanisms*
}

Neide Kalil Gaspar ${ }^{1}$

DOI: http://dx.doi.org/10.1590/abd1806-4841.20165029

Abstract: The transforming growth factor-beta 1 (TGF $\beta 1$ ) promotes fibrosis, differentiating epithelial cells and quiescent fibroblasts into myofibroblasts and increasing expression of extracellular matrix. Recent investigations have shown that PPAR (peroxisome proliferator-activated receptor*) is a negative regulator of fibrotic events induced by TGF $\beta 1$. Dehydroepiandrosterone (DHEA) is an immunomodulatory hormone essential for PPAR functions, and is reduced in some processes characterized by fibrosis. Although scarring alopecia characteristically develops in the female biological period in which occurs decreased production of DHEA, there are no data in the literature relating its reduction to fibrogenic process of this condition. This article aims to review the fibrogenic activity of TGF $\beta 1$, its control by PPAR and its relation with DHEA in the frontal fibrosing alopecia.

Keywords: DHEA; FFA; Frontal fibrosing alopecia; Alopecia; Dehydroepiandrosterone; PPAR gamma; Transforming growth factor alpha

\section{INTRODUCTION}

The frontal fibrosing alopecia (FFA) is a form of alopecia manifested in women, very rarely in men, and it begins in frontal hairline, progressing in the lateral and posterior direction, with permanent loss of hair follicles and may reach also the eyebrows and other areas. ${ }^{1}$

Of unknown etiology and treatment with unsatisfactory results, it was recently compared to a similar type of hair loss found in mutant animals presenting changes in functions of specific intranuclear receptors.

The occurrence of this event almost exclusively in women, and those in the pre or post-adrenopause period, raises the need to relate the hormonal changes concerning the development of alopecia.

Even maintaining the present article under "review article" designation, only the essential facts to the current conceptualization of the disease are presented, leaving more space for the aspects that are considered relevant:

a) Is the reduction of the local activity of dehydroepiandrosterone (DHEA) responsible for fibrosis and loss of hair follicles?

b) May DHEA for topical use be useful in its treatment?

\section{HISTORY}

In 1994, Steven Kossard described a new and peculiar hair loss called the frontal fibrosing alopecia of women (FFA). ${ }^{1}$ Its histology was similar to lichen planopilaris (LPP), without the occurrence of signs of lichen planus in the rest of the tegument. Sixteen years before Josefowicz identified a mutant species of mouse, named Asebia, with alopecia and atrophy of sebaceous glands. ${ }^{2}$ Genetic aspects related to alopecia in these mice were mapped in a second mutant animal, the Asebia 2, spontaneously developed in laboratory and with extreme atrophy of sebaceous glands and hair follicles progressing to fibrosis. ${ }^{3}$

The genotype of these animals, with changes resulting from chromosome 11 mutations, was identified, evidencing the entire follicular degeneration process. ${ }^{4}$ The fact that the activity of PPAR $\alpha$ and $\gamma$ was essential for the differentiation and functions of sebocytes was followed by identification of malfunctions of these receptors in Asebia $2 .^{5}$

It has been shown that deletion of PPAR $\gamma$ in the follicular bulge generated changes similar to LPP. ${ }^{6}$ Similarly, the finding that the functional maintenance of hair follicles depends on the presence of multipotent cells in the bulge demonstrated the importance of investigating the effect of stimulant drugs of PPARs in the treatment of alopecia.?

The fibrosing inflammatory follicular changes in Asebias were reviewed and appraised as not autoimmune. Stem cell markers aberrations in the follicles during the cell cycle were demonstrated and accountable for the changes presented. ${ }^{8}$ The exact 
etiopathogenic relation between FFA and LPP is not established, and the various tested treatments have only stopped the process of expanding in inconstant percentage of cases. ${ }^{9}$

\section{EPIDEMIOLOGICAL AND CLINICAL ASPECTS}

Re-evaluating 355 cases in a multicenter study, only 12 were men, 49 were women with early menopause and 49 were premenopausal women. In $37 \%$ patients, alopecia was found to be severe. Mean age was 61 years (between 23 and 86 years). ${ }^{10}$

FFA is characterized in its early stages by retraction of the previous limit of hairline, with evolution in lateral and posterior direction, and may present erythema, micropapules and hyperkeratosis in the follicles. Mild skin atrophy, itching and burning sensation may occur in some patients, as well as partial and even total loss of eyebrows. The final result is a scarring aspect in the affected area. The progression of the process is slow and spontaneous remission may occur. Lesions in other areas of the scalp have been described. Loss of eyebrows occurred in $73 \%$ of patients, of eyelashes in $3 \%$, and of hair body in $25 \%$ of 60 patients. ${ }^{11}$ In a series of 16 cases, 8 presented loss in eyebrows and 6 presented axillary alopecia. ${ }^{12}$

\section{DERMATOSCOPIC DIAGNOSIS}

Dermoscopy can indicate the area of biopsy and should be performed where there is perifollicular concentric scales that are less scaly than LPP. Perifollicular erythema is indicative of disease progression and may be present in other scarring alopecia, such as discoid lupus erythematous and LPP. Keratosis pilaris is also common to discoid lupus erythematosus. ${ }^{13-15}$ In the lesions of 79 women, $72.1 \%$ showed hyperkeratosis, $66.3 \%$, perifollicular erythema, and $44.8 \%$, follicular plugs. ${ }^{16}$ Erythema and perifollicular scales indicate progressive disease activity. ${ }^{14}$ There is progressive loss of follicles with perifollicular erythema with and without scales. The absence of follicular ostia is the ultimate characteristic feature. ${ }^{17}$ Within a 249 case review, there was presence of follicular hyperkeratosis in $89 \%$ of them, perifollicular erythema in $77 \%$, isolated hair in $67.9 \%$, diversity of diameters in $45 \%$, scarring white patches in $22.3 \%$ and yellow dots in $21.9 \% .^{18}$

\section{HISTOPATHOLOGICAL DIAGNOSIS}

Biopsy reveals the presence of lymphocytic infiltrate involving the bulge and the infundibulum. Apoptotic cells in the outer sheath of the rod and concentric fibrosis around the follicle with decrease in the follicle number, replaced by fibrous tissue, are present. ${ }^{19}$ The location of the infiltrate is centered in the bulge region. ${ }^{20}$ These aspects occur in LPP and although there is no clear tissue difference between LPP and FFA, there is milder inflammation and apoptosis in FFA than in LPP. ${ }^{20,21}$

\section{TREATMENT}

Stabilization of the anterior limit of the implant can be achieved with intralesional corticosteroids in most patients. ${ }^{22}$ Stand-alone topical corticosteroids are not effective. ${ }^{23}$ Evaluating 15 patients, hydroxychloroquine at a dose of $400 \mathrm{mg} /$ day led to a reduction of signs and symptoms in 11 of them, reached between 6 and 12 months of administration. ${ }^{24}$
Among the 22 cases of LPP with pioglitazone ministration, only four are presented as FFA, and three of them reacted to treatment. ${ }^{25}$

Systemic anti-inflammatory drugs, tacrolimus, tetracyclines, cyclosporine, mycophenolate mofetil, combined or not with other substances, have been used in small case series, with varied responses.

Antimalarials, intralesional steroids and antiandrogens are the most often cited as being able to stop the progression of FFA. ${ }^{10,26-28}$

In the extensive review of Vano-Galvan et al., the antiandrogens have the best results in controlling the progression of the disease. In the experience of these authors, intralesional corticosteroids associated with antiandrogens were useful in the presence of erythema or follicular hyperkeratosis. ${ }^{10}$ Only this process of stabilization is reported in response to different treatments tested.

The transplantation of hair follicles can have results in cases of disease in remission. ${ }^{29}$

\section{PHYSIOPATHOLOGY: MOLECULAR MECHANISMS}

Integrity and functions of sebaceous gland are essential for the development and activity of hair follicles ${ }^{4}$ stimulated by PPAR $\gamma .{ }^{5}$ Mice depleted of the gene of this receptor lose the stem cells of the bulges and develop fibrosing alopecia., ${ }^{5,6}$ PAR $\gamma$ is indispensable for the maintenance of stem cells of functional epithelium in hair follicles. ${ }^{5}$ Deletion of the PPAR $\gamma$ gene in the bulge area of the hair resulted in a skin process is similar to LPP alopecia. ${ }^{6}$ The location of the inflammatory infiltrate is typically centered on the bulge region. ${ }^{21}$

Patients with LPP have changes of expression of this gene, indicative of defect in lipid metabolism and of peroxisomes biogenesis. ${ }^{7}$ The comparative analysis of biopsies in areas with scarring alopecia and unaffected areas of patients revealed a decrease in expression of genes required for lipid metabolism and biogenesis of PPAR. In lesions of FFA, there is increasing loss of these receptors, pro-inflammatory lipid accumulation, inflammatory cell infiltration and destruction of follicular units. ${ }^{7}$

There is considerable evidence on the role of PPAR $\gamma$ and its ligands in inhibiting fibrosis in different organs and tissues. ${ }^{30-33}$ These nuclear receptors act as lipid sensors to modulate gene expression. Thus, they participate of the main metabolic and inflammatory tissue regulations, with extensive physiological and pathological consequences, as well as in important regulatory processes of cell fate. $^{34}$

Three receptor subtypes, $\alpha, \beta$ and $\gamma$, phylogenetically related, but encoded by different genes, have been identified with predominant roles in the PPAR family. PPAR $\gamma$ is more expressed in the sebaceous glands and adipose tissue, and less frequently in the colon, adrenal glands, spleen, and skin. In these sites, PPAR $\gamma$ mediates storage of fatty acids. It also regulates lipogenesis, local inflammatory and carcinogenic response, sebocytes and keratinocytes differentiation, wound healing and positive response to the ultraviolet irradiation. ${ }^{35-39}$

PPARs are abundant in the adult epidermis and their activation induces intense proliferation of peroxisomes. A growing body of research indicates that the $\gamma$ subtype of the PPAR (PPAR $\gamma$ ) is the 
key to control the activity of TGF $\beta 1$ in suppressing fibrogenesis. The imbalance of its control in skin fibroproliferation is responsible for excessively fibrous activities. ${ }^{38}$

TGF $\beta 1$ is a pro-oncogenic cytokine that leads to epithelial/ mesenchymal transdifferentiation and to fibroblast/myofibroblast transition, a crucial event for collagen synthesis. ${ }^{39-42}$ The development of fibrosis after tissue injury requires activation of TGF $\beta 1 .{ }^{42}$

Currently, it is accepted that the epithelial/mesenchymal transition, primarily described in critical stages of embryogenesis, may occur both in development of tumors and in non-tumor tissues, by the action of TGF $\beta 1$, together with different local growth factors. ${ }^{41}$ This transition, concomitant with increased TGF $\beta 1$, is carried out via SMAD protein, transducer of the extracellular signal, increasing the production of reactive oxygen species (ROS) in the cytoplasm and mitochondria. ${ }^{42,43}$

These facts have led researchers to experiment with different drugs with the potential to stimulate PPAR $\gamma$ in vitro in the treatment of LPP and also aiming to develop therapeutics of fibrotic processes in different organs. ${ }^{28,30-33,35-37,43-46}$ However, PPAR activity in hair follicles have not been investigated in relation to hormonal changes typical of adrenopause.

In recent years, various investigations have established that stimulation of endocrine PPARs is especially related to the activity of dehydroepiandrosterone. DHEA and its sulfated product (DHEAS) are the most abundant circulating steroid hormones in humans. Its production in women have higher levels between 25 and 30 years, decreasing after reaching this stage and reaching adrenopause at 60 years, with only $10 \%$ to $20 \%$ of peak levels. ${ }^{47}$

DHEA performs immunomodulatory role and is essential for the nuclear receptor PPAR in the transcription of genes, in fat metabolism, and in mitochondrial activity ${ }^{48-49}$ The imbalance of its functions can trigger inflammatory and autoimmune changes. ${ }^{48}$

DHEA is synthesized in several somatic sites, such as adrenal cortex, ovarian theca and brain. Skin cells have all the biochemical structure necessary for the production of glucocorticoid, estrogen and androgens. This synthesis can be performed from systemic origin precursors or, alternatively, through conversion of cholesterol to pregnenolone and its subsequent transformation to biologically active steroids. ${ }^{50}$ Disorders in cutaneous steroidogenesis may have local and systemic effects, triggering inflammatory or autoimmune processes. $^{50}$

Cutaneous steroidogenesis, which mainly occurs in the sebaceous gland, has a distinct pattern of evolutionary topographic behavior during the aging process, as evidenced by studies conducted only in males. DHEA and androstenedione concentrations measured in the liquid content of suction blisters in different areas of the body were compared to the blood level in young men $(27,8$ years) and elderly subjects (62.6 years). Increased concentration of DHEA was found, and not of androstenedione, in the liquid of the blisters of the elderly subjects, inversely to reduced blood levels. In the studied skin sites, the differences between young and old individuals were higher. ${ }^{51}$ Similar tissue studies in women have not been found in the literature.

The importance of the effect of DHEA on mitochondrial oxidative metabolism was stabilished by administration of this hormone in rats. These animals showed increased liver and brain metabolism with elevated brain weight without concurrent increase in body weight..$^{52}$ The results observed in the topographic response is demonstrative of the variation in distribution of DHEA receptors in the body of these animals.

Tests with radioactive DHEA administered to dogs confirmed their higher metabolism in fibroblasts derived from dermal follicles and, among these, in dermal fibroblasts derived from the follicles of the skulls of the animals, accentuating the topographic differences of their receptors. ${ }^{53}$

The relation between the activity of DHEA and FFA is also suggested by the reduction of DHEA levels in different conditions characterized by fibrosis, such as occurs in idiopathic pulmonary fibrosis. ${ }^{47}$ A comparison of the serum levels of DHEA/DHEAS of 137 patients with idiopathic pulmonary fibrosis and 58 controls showed a significant reduction of these hormones in patients, both in plasma and in the bronchoalveolar lavage fluid.

The importance of DHEA in the fibrogenic process was also demonstrated by the addition of DHEA to cultured fibroblasts obtained from bronchoalveolar lavage from patients, which resulted in the lowest differentiation in myofibroblasts and decrease in collagen production and duplication of apoptosis levels compared to cultivated ones without the addition of hormone. ${ }^{47}$ Idiopathic fibrosis is a disease related to aging and is characterized by expansion of myofibroblasts and lung remodeling. ${ }^{47}$

Epithelial/mesenchymal transition also develops in chronic asthma with great impact on the bronchial functions. Bronchial epithelial cells of the human lineage 16HBE-14, induced to fibrosis by TGF $\beta 1$, were prevented from developing it by adding DHEA to their cultivation. ${ }^{38,40}$

The importance of DHEA was further corroborated by the addition of supraphysiological doses of this hormone to the cultivation of HepG2 cell line of human hepatoma, with substantial response of PPAR gene expression in both the transcriptional as in post-transcriptional level. ${ }^{54}$

Having found that the essential fact in FFA is the dysfunction of PPAR $\gamma$ and that the function of this receptor is linked to stimulation of DHEA, it is vital to define its participation in the development of fibrosis in this alopecia. However, in the medical literature, there is no information on the relation between the fibrogenic process of FFA and endocrine changes of adrenopause regarding DHEA.

\section{DISCUSSION}

The exposed aspects that relate to fibrogenic activity to reduction of PPARs function and their dependence of the activation by DHEA, lead us to suppose that the reduced activity of this hormone, characteristic of the phase in which this alopecia occurs, correlates directly to fibrogenic inflammatory process of FFA.

Knowing that the activity of a hormone depends on both its blood content as the functional integrity of specific cellular receptors, and that these are presented in topographic and individual variation, the simple blood hormonal evaluation does not reflect the degree of their local operations. Thus, verification of their functions in the lesional areas becomes necessary. 
It is possible that the benefits obtained by the administration of $5 \alpha$-reductase inhibitors in the FFA are the result of DHEA impediment in reaching its final conversion to dihydrotestosterone.

The exact relation between FFA and LPP is not established. Although Samrao ${ }^{23}$ has reported the presence of lichen planopilaris in $14 \%$ of 36 cases, MacDonald et al. found it only in $1.6 \%$ in a series of 60 cases of FFA. ${ }^{11,23}$ Although in some patients with typical clinical aspect of FFA occur the presence of lichen planopilaris, it is essential to answer the following questions:

a) Why almost all cases of FFA are presented in adrenopause women?

b) What are the differences between the pathogenic processes underlying to LPP and FFA?

c) If in FFA the hypothesis of this article is confirmed, should it also be extended to LPP lesions?

\section{CONCLUSIONS}

1. PPAR $\gamma$ is the main regulator of lipid cell metabolism and sebocytes development. The reduction of its activity is responsible for fibrosis;

2. DHEA is an important stimulator of PPARs;

3. Reduction of DHEA is observable in some diseases characterized by fibrosis;

4. Frontal fibrogenic alopecia typically develops in the woman life period in which production of DHEA is decreased;

5. It is possible that the reduction of the local activity of DHEA is responsible for follicular fibrogenic process of this alopecia;

6. It is also possible that the better understanding on the variation of topography dynamic of tissue activity of DHEA changes therapeutic strategies in other conditions characterized by fibrosis.

\section{REFERENCES}

1. Kossard S. Postmenopausal frontal fibrosing alopecia. Scaring alopecia in a pattern distribuction. Arch Dermatol. 1994;130:770-4.

2. Josefowicz WJ, Hardy MH. The expression of the gene asebia in the laboratory mouse. I. Epidermis and dermis. Genet Res. 1978;31:53-65.

3. Sundberg JP, Boggess D, Sundberg BA, Eilertsen K, Parimoo S, Filippi M, et al. Asebia-2J (Scd1(ab2J)): a new allele and a model for scarring alopecia. Am J Pathol. 2000;156:2067-75.

4. Porter RM, Jahoda CA, Lunny DP, Henderson G, Ross J, McLean WH, et al. Defolliculated (dfl): a dominant mouse mutation leading to poor sebaceous gland differentiation and total elimination of pelage follicles. $J$ Invest Dermatol. 2002;119:32-7.

5. Rosenfield RL, Kentsis A, Deplewski D, Ciletti N. Rat preputial sebocyte differentiation involves peroxisome proliferator-activated receptors. J Invest Dermatol. 1999;112:226-32.

6. Karnik P, Tekeste Z, McCormick TS, Gilliam AC, Price VH, Cooper KD, et al. Hair follicle Stem cell-specific PPARgamma delection causes scarring alopecia. J Invest Dermatol. 2009;129:1243-57.

7. Harries MJ, Paus R. Scarring alopecia and the PPAR-gamma connection. J Invest Dermatol. 2009;129:1066-70.

8. Ruge F, Glavini A, Gallimore AM, Richards HE, Thomas CP, O'Donnell VB, et al. Delineating immune-mediated mechanisms underlying hair follicle destruction in the mouse mutant defolliculated. J Invest Dermatol. 2011;131:572-9.

9. Chew AL, Bashir SJ, Wain EM, Fenton DA, Stefanato CM. Expanding the spectrum of frontal fibrosing alopecia: a unifying concept. J Am Acad Dermatol. 2010;63:653-60

10. Vañó-Galván S, Molina-Ruiz AM, Serrano-Falcón C, Arias-Santiago S, RodriguesBarata AR, Garnacho-Saucedo G, et al. Frontal fibrosing alopecia: a multicenter review of 355 patients. J Am Acad Dermatol. 2014;70:670-8.

11. MacDonald A1, Clark C, Holmes S. Frontal fibrosing alopecia: a review of 60 cases. J Am Acad Dermatol. 2012;67:955-61.

12. MacDonald A, Clark C, Holmes S. Frontal Fibrosing Alopecia: a survey in 16 patients, Eur Acad Dermatol Venereol. 2005;119:796-5.

13. Miteva M, Tosti A. Hair and scalp dermatoscopy. J Am Acad Dermatol. 2012;67:1040-8.

14. Toledo-Pastrana T, Hernández MJ, Camacho Martínez FM. Perifollicular erythema as a trichoscopy sign of progression in frontal fibrosing alopecia. Int J Trichology. 2013;5:151-3

15. Duque-Estrada B, Tamler C, Sodré CT, Barcaui CB, Pereira FB. Dermosccopy patterns of cicatricial alopecia resulting from discoid lúpus erythematosus and lichen planopilaris. An Bras Dermatol. 2010;85:179-83.

16. Jouanique $\mathrm{C}$, Reygagne P. Frontal fibrosing alopecia. Ann Dermatol Venereol. 2014;141:272-8.

17. Inui S, Nakajima T, Shono F, Itami S. Dermoscopic findings in frontal fibrosing alopecia: report of four cases. Int J Dermatol. 2008;47:796-9.

18. Fernández-Crehuet $P$, Rodrigues-Barata AR, Vañó-Galván $S$, Serrano-Falcón $C$ Molina-Ruiz AM, Arias-Santiago S, et al. Trichoscopy features of frontal fibrosing alopecia: results in 249 patients. J Am Acad Dermatol. 2015;72:357-9.

19. Poblet $E$, Jiménez $F$, Pascual $A$, Piqué E. Frontal fibrosing alopecia versus lichen planopilaris: a clinicopathological study. Int J Dermatol. 2006;45:375-80.

20. Baibergenova A, Donovan J. Lichen planopilaris: update on pathogenesis and treatment. Skinmed. 2013;11:161-5.

21. Banka N, Mubki T, Bunagan MJ, McElwee K, Shapiro J. Frontal fibrosing alopecia: a retrospective clinical review of 62 patients with treatment outcome and longterm follow-up. Int J Dermatol. 2014;53:1324-30.

22. Rácz E, Gho C, Moorman PW, Noordhoek Hegt V, Neumann HA. Treatment of frontal fibrosing alopecia and lichen planopilaris: a systematic review. J Eur Acad Dermatol Venereol. 2013;27:1461-70.

23. Samrao A, Chew AL, Price V. Frontal fibrosing alopecia: a clinical review of 36 patients. Br J Dermatol. 2010;163:1296-300.

24. Georgala S, Katoulis AC, Befon A, Danopoulou I, Georgala C. Treatment of postmenopausal frontal fibrosing alopecia with oral dutasteride. J Am Acad Dermatol. 2009;61:157-8.

25. Shapiro R, Shapiro P. Hairline design and frontal hairline restoration. Facial Plast Surg Clin North Am. 2013;21:351-62.

26. Olszewska M, Rudnicka L. Effective treatment of female androgenic alopecia with dutasteride. J Drugs Dermatol. 2005;4:637-40.

27. Ladizinski B, Bazakas A, Selim MA, Olsen EA. Frontal fibrosing alopecia: a retrospective review of 19 patients seen at Duke University. J Am Acad Dermatol. 2013;68:749-55

28. Mesinkovska NA, Tellez A, Dawes D, Piliang M, Bergfeld W. The use of oral pioglitazone. J Am Acad Dermatol. 2015;72:355-6.

29. Galli A, Crabb DW, Ceni E, Salzano R, Mello T, Svegliati-Baroni G, et al. Antidiabetic thiazolidinediones inhibit collagen synthesis and hepatic stellate cell activation in vivo and in vitro. Gastroenterology. 2002;122:1924-40.

30. Masamune A, Kikuta K, Satoh M, Sakai Y, Satoh A, Shimosegawa T. Ligands of 
peroxisome proliferator-activated receptor-gamma block activation of pancreatic stellate cells. J Biol Chem. 2002;277:141-7.

31. Burgess HA, Daugherty LE, Thatcher TH, Lakatos HF, Ray DM, Redonnet M, et al. PPARgamma agonists inhibit a induced pulmonary myofibroblast differentiation and collagen production: implications for therapy of lung fibrosis. Am J Physiol Lung Cell Mol Physiol. 2005;288:L1146-53.

32. Zafiriou S, Stanners SR, Saad S, Polhill TS, Poronnik P, Pollock CA. Pioglitazone inhibits cell growth and reduces matrix production in human kidney fibroblasts. J Am Soc Nephrol. 2005;16:638-45.

33. Feige JN, Gelman L, Michalik L, Desvergne B, Wahli W. From molecular action to physiological outputs: peroxisome proliferator-activated receptors are nuclear receptors at the crossroads of key cellular functions. Prog Lipid Res. 2006;45:120-59.

34. Ninomiya I, Yamazaki K, Oyama K, Hayashi H, Tajima H, Kitagawa H, et al. Pioglitazone inhibits the proliferation and metastasis of human pancreatic cancer cells. Oncol Lett. 2014;8:2709-2714.

35. Mao-Qiang M, Fowler AJ, Schmuth M, Lau P, Chang S, Brown BE, et al. Peroxisome-proliferator-activated receptor (PPAR)-gamma activation stimulates keratinocyte differentiation. J Invest Dermatol. 2004;123:305-12.

36. Schmuth M, Haqq CM, Cairns WJ, Holder JC, Dorsam S, Chang S, et al. Peroxisome proliferator-activated receptor (PPAR)-beta/delta stimulates differentiation and lipid accumulation in keratinocytes. J Invest Dermatol. 2004;122:971-83.

37. Leask A. The Contribution of Peroxisome Proliferator-Activated Receptor Gamma to Cutaneous Wound Healing. Adv Wound Care (New Rochelle). 2013;2:69-73.

38. Ham SA, Kang ES, Lee H, Hwang JS, Yoo T, Paek KS, et al. PPAR inhibits UVB-induced secretion of MMP-1 through MKP-7-mediated suppression of JNK signaling. J Invest Dermatol. 2013;133:2593-600.

39. Xu L, Xiang X, Ji X, Wang W, Luo M, Luo S, et al. Effects and mechanism of dehydroepiandrosterone on epithelial-mesenchymal transition in bronchial epithelial cells. Exp Lung Res. 2014;40:211-21.

40. Ishikawa F, Kaneko E, Sugimoto T, Ishijima T, Wakamatsu M, Yuasa A, et al. A mitochondrial thioredoxin-sensitive mechanism regulates TGF- $\beta$-mediated gene expression associated with epithelial-mesenchymal transition. Biochem Biophys Res Commun. 2014;443:821-7.

41. Pawlak M, Baugé E, Bourguet W, De Bosscher K, Lalloyer F, Tailleux A, et al. The transrepressive activity of peroxisome proliferator-activated receptor alpha is necessary and sufficient to prevent liver fibrosis in mice. Hepatology. 2014;60:1593-606.

42. Ghosh AK, Bhattacharyya S, Wei J, Kim S, Barak Y, Mori Y, et al. Peroxisome proliferator-activated receptor-gamma abrogates Smad-dependent collagen stimulation by targeting the p300 transcriptional coactivator. FASEB J. 2009;23:2968-77.

43. Mirmirani P, Karnik P. Lichen planopilaris treated with a peroxisome proliferatoractivated receptor gamma agonist. Arch Dermatol. 2009;145:1363-6.

44. Zhang J, Fang NY, Gao PJ, Wu LY, Han WQ, Guo SJ, et al. Peroxisome proliferatoractivated receptor-gamma agonists attenuate angiotensin II-induced collagen type I expression in adventitial fibroblasts. Clin Exp Pharmacol Physiol. 2008;35:72-7.

45. Chen XQ, Liu X, Wang QX, Zhang MJ, Guo M, Liu F, Pioglitazone inhibits angiotensin II-induced atrial fibroblasts proliferation via NF-кB/TGF- $\beta 1 /$ TRIF/TRAF6 pathway. Exp Cell Res. 2015;330:43-55.

46. Hao GH, Niu XL, Gao DF, Wei J, Wang NP. Agonists at PPAR-gamma suppress angiotensin II-induced production of plasminogen activator inhibitor-1 and extracellular matrix in rat cardiac fibroblasts. Br J Pharmacol. 2008;153:1409-19.

47. Mendoza-Milla C, Valero Jiménez A, Rangel C, Lozano A, Morales V, Becerril C, et al. Dehydroepiandrosterone has strong antifibrotic effects and is decreased in idiopathic pulmonary fibrosis. Eur Respir J. 2013;42:1309-21.

48. Hazeldine J, Arlt W, Lord JM. Dehydroepiandrosterone as a regulator of immune cell function. J Steroid Biochem Mol Biol. 2010;120:127-36.

49. Patel MA, Katyare SS.5. Effect of dehydroepiandrosterone (DHEA) treatment on oxidative energy metabolism in rat liver and brain mitochondria. A dose-response study. Clin Biochem. 2007;40:57-65

50. Slominski A, Zbytek B, Nikolakis G, Manna PR, Skobowiat C, Zmijewski M, et al. $\mathrm{J}$ Steroid Biochem Mol Biol. Steroidogenesis in the skin: implications for local immune functions. J Steroid Biochem Mol Biol. 2013;137:107-23.

51. Patel MA, Katyare SS. Dehydroepiandrosterone (DHEA) treatment stimulates oxidative energy metabolism in the cerebral mitochondria from developing rats. Int J Dev Neurosci. 2006;24:327-34.

52. Haag M, Hamann T, Kulle AE, Riepe FG, Blatt T, Wenck H, et al. Age and skin site related differences in steroid metabolism in male skin point to a key role of sebocytes in cutaneous hormone metabolism. Dermatoendocrinol. 2012;4:58-64.
53. Bamberg E, Aichinger A, Mitteregger G. In vitro metabolism of dehydroepiandrosterone and testosterone by canine hair follicle cells. Vet Dermatol. 2004;15:19-24.

54. Poczatková H, Bogdanová K, Uherková L, Cervenková K, Riegrová D, Rypka M, Dehydroepiandrosterone effects on the mRNA levels of peroxisome proliferatoractivated receptors and their coactivators in human hepatoma HepG2 cells. Gen Physiol Biophys. 2007;26:268-74.

\author{
MAILING ADDRESS: \\ Neide Kalil Gaspar \\ R. Mariz e Barros, 297 - Icaraí \\ 24220-210 - Niterói - RJ \\ Brazil \\ Mailing address: neide2605@yahoo.com.br
}

How to cite this article: Gaspar NK. DHEA and frontal fibrosing alopecia: molecular and physiopathological mechanisms. An Bras Dermatol. 2016;91(6):776-80. 